\title{
Part I CLASSROOM RESEARCH
}

At the 1987 POD meeting, Pat Cross challenged us to discover what could be learned by encouraging faculty to become researchers in their own classrooms, answering their own questions empirically, whether through formal or informal investigations. Classroom research is not new to POD members as previous editions of this volume attest. In characteristic POD fashion, several of our members stepped up their efforts in response to Cross's challenge. The results of their inquiries are presented here.

"Project Learn" describes a POD-funded program involving seven faculty members who identified their students' learning styles, then devised, implemented, and tested alternative teaching strategies to address their students needs. The University of Rhode Island project brought together a group of faculty who had already "graduated" from the regular URI faculty development program and who were in search of a new way to think about their teaching. The diversity of their projects is enhanced by their honest assessments of the benefits as well as the problems that arise when faculty engage in classroom research.

Finally, Ron Smith and Fred Schwartz provide an inside look at a very intense moment of self-disclosure and self-discovery by a teacher exploring her relationship with a student. The care and detail of their analysis admittedly make it a challenge to read. Using Argyris and Schon's model of the reflective practitioner, they illustrate how unarticulated, untested assumptions can be surfaced through dialogue so that their role in practice - and their implications for personal integrity - can be revealed. 